\title{
ATM INFUSION: LIFE IN THE CAGE OF CORPORATE CULTURE
}

\author{
A B S T R A C T
}

This article is critical discourse on new redefined relations and usage of urban public spaces. Its starting points are the new relations between public and private spheres in contemporary U.S. cities which are based on corporate doctrine of consumer's lifestyle and phenomenon of exploitation of public resources, with the goal to accumulate more private capital. In that sense, focus was on tensions between public and private and phenomenon of city centre where the private is imposed as public with its own rules of using and consuming instant entertainment and consumption. Phenomenon of public space as the only democratic space where everyone are equal, suddenly become phenomenon of the space for 'voluntarily' exploitation of people and resources with the idea of accumulating the private capital. 
„One day Walt Disney had a vision. It was a vision of a place where children and parents could have fun together. The more Walt dreamed of a "magical park," the more imaginative and elaborate it became." Is it really true that our destiny is on the way to Disneyland?

\section{INTRODUCTION}

Global changes in the area of economic relations came with post-industrial society through establishing corporate culture and imperative of consumer's lifestyle. These changes not only influenced the life of individuals, but redefined the relations in public sphere and public space in which corporate culture acts. Transformed corporative activity, with the assistance of modern technology, has moved from factory halls in the sector of media, culture, art and internet, that is, in the public space which became the channel or the place for accumulation of capital. Accordingly, in physical context, public city spaces for the first time got very important treatment, because they became tools for marketing of goods and services. Industrial halls were turned in the brown fields for culture and art development, so called „, cultural industry“ and public city spaces became created polygons for positioning of private capital and interest, destination for the tourists horde, place for amusement, marketing and modeling of consumer's lifestyle. Instant culture as the main means for exploitation and extra profit has never been so promoted in history but in these newly established dehumanized relations and public spaces, where the public interest is backed out and where the private interest is taking over and establishing discriminatory rules, languages and behaving. These dehumanized public spaces became the main 'battlefields' for the survival of free cities and free city life. Disneylandization of cities, based on the human and city government weaknesses, is realized through acting of private and/or public capital in public city spaces that got commercialized and turned into industry of entertainment and spectacle, in the institutional frame of Business Improvement District (BID). Is it true that the contemporary cities came in the position where local authorities and public services are not capable to take care of public interest and they have to give away that role to private capital? Is our destiny really in the train going to Disneyland?

\section{ACTUAL OR APPARENT REALITY}

Disneyland and Disney's world are not only the most known public spaces of the second half of 20th century, but conceptual basis of today's social values that are framing and giving contents to life of modern man/woman. Disney's 
company has introduced revolution and established foundation for the economy of technology and amusement. Disney's thematic parks rise over ethnical, class and regional identities, offering in return national public culture based on aesthetization of differences and fear control ${ }^{2}$. Disney's world is created in the way to become something inevitable, alter ego to modern western societies and collective fantasizes which are sources of many myths that the modern society is based on. This world is actually the materialization of the Hollywood "happy end" idea, the movie with continuous happy ending as the opium for the brain and deception for the eyes.

It is generally known assumption that production, more than culture is main driving force of economy. However, the concept of Disney's entertainment world is lean on extensive labor force and expansive network of material resources ${ }^{3}$. Surely, this has provoked urban development of cities, giving them hope that the different world is possible. ${ }^{4}$ Visual coherency of Disney's thematic parks will create public culture of citizenship and safety that the world has never known until then. Therefore, ideal world without weapon, homeless, drugs, visible repressive political authorities, will become illusionary real in Disney's world up to the point to make strong influence on modern society by becoming model base, prototype of relations that represent foundation of all dominant movements in development and revitalization of contemporary cities.

Atmosphere of Disney's world, based on complex of physical surrounding, technology and services, is affecting the consumer as opium, creating the illusion that it is possible to create real world to which Disney's amusement world would be imminent. Accordingly, thematic parks are offering to different populations (from tourists to labor force that is serving) one type of deception/ delusion fraud that they are feeling good just because they are exactly there, sending, along the way, strong and clear message that can only be understand as an false alternative and shelter for contemporary man/woman. This apparent hybrid world represents a non- place, a space out of physical and social context, anti-geographical space, something which is self-sufficient, that can serially be multiplied not only physical, but in the contents as well. On the other hand, Disney's is fascinating with its idealization of urban public space as the issue based on visual culture, safety and private management. This means, well arranged and maintained public city spaces without homeless and criminal, with highly esthetical surrounding, are the new requirements that the newly created corporate culture imposed to city government. Local administration, especially in big cities, doesn't have the possibility to meet those high 
requirements, so they create pre/conditions for establishment of partnerships between public and private sector for Business Improvement District - BID. BID is based on Disney's experience on establishment the synergy between different investors that has served as the model for creation of new economic relations based on economy of media, real estate, and visual arts in public spaces. Disney's world, no matter it is apparent reality, illusion, has redefined and created new relations in urban planning and management, at the beginning in USA and Europe, and later in the whole capitalist world.

Primordial need of the man/woman for community and aspiration to quality and high status are basic postulates of global corporative culture that influencing as an opium to modern society, giving it that illusion through thematic parks, i.e. shopping molls chains and centers. Private corporations, knowing that the new symbol of encounters and gatherings is trade, are creating different spaces for «public» usage, like atriums, plazas and halls with numerous of art works and exhibitions, social and trade services. Accordingly, phenomenon of Disney's world in which public is going together with trade will become basic and main model for private corporations and urban development of contemporary cities in order to satisfy much more needs of corporative culture.

\section{ACTUAL REALITY - Business Improvement District (BID)}

BID idea has started at the beginning of sixties of the last century, first in Canada, i.e. USA and later it spread in Great Britain and Europe. BID is the most developed in the countries with strong market orientation. In USA, BID is created in cities with an approximately 100.000 citizens, and with this more than $25 \%$ of cities with BID have more than 700.000 citizens. There are different BIDs in USA in relation to the size that is involved; the biggest ones are covering the space of 300 blocks with the number of full time employees that is over 150. Structure of BID in USA consists of $61 \%$ non-profit organizations, $13 \%$ public sector and 26\% public-private sector partnerships. Depending of city size and number of BID involved blocks, their budget is between $8.000 \$$ to more than 15 million, while the average is around $200.000 \$ .^{5}$

Basic aspects of BID functioning can be revised through promotion of «pure and safe», through lobbing at local political level. In that sense, according to some indexes, more than $75 \%$ BID are promoting consumerism (organizing different events and advertising material for sale), while $50 \%$ are investing into urban equipment and greenery, i.e. maintenance, and is lobbing with local politicians and promoting public policy in local community. BIDs are the least 
involved (about $6 \%$ ) into sphere of social activities like homeless care, youth services and trainings for new jobs. ${ }^{6}$

The biggest and the most complex BID network in USA is developed in NYC (Alliance for Downtown New York) where currently is functioning more than 60 organized BIDs with annual budget bigger than 80 millions of dollars and more than 70.000 entrepreneurs in 5 city districts (Bronx, Brooklyn, Manhattan, Queens and Staten Island). ${ }^{7}$ For sure, one of the most known BIDs in NYC is Times Square, the most known place and public space in the world. Transformation of Times Square has started in early 70-ies of the last century and it continues until today. During the past period, cheap restaurants, small businesses and small buildings were replaced by thematic restaurants, television studios, hotels and places for fun. Big LCD and LED screens and shops of modern brands, and well planned image, have contributed Times Square to become the most desirable space for tourists in the world, visited by millions of people daily. Times Square transformation has been done through combination of design and change of certain regulations related to public spaces. Using the Disney's concept, New Times Square has been created as a prototype of corporative culture and new reading of the city that will become a world's icon with the time, personification of contemporary American city. In this biggest created Disney's world until today in which, not by a chance, Disney appears as one of the leading mega corporations in this district. Beside Disney, significant influence in New Times Square, have ABC network, than ESPN Zone, MTV, NBC, and Viacom which appears as the major owner of outer advertising spaces. New Times Square as a meeting point of huge capital which is the measure of political freedom, that is, of independence from local city government, has specific rules of behaving as well as its own Security Guards with the powers to have away personae non gratae (homeless people) and to arrest them. In one moment, even ad-hoc courts were established here.

Transformed New Times Square, apart of new rules, has established "new" moral that is not directed to familiar and friendly pseudo surroundings, but completely the opposite, it become the place with pictures that exploit women's body and texts with elements of violence. ${ }^{8}$ The transformation hasn't brought new quality for local community, but public interests are subordinated to interests of big capital. Disneylandization, arrival of big corporations and creation of public space as spectacle with the goal to attract lot of tourists and consumers with exclusive corporative priorities, regardless of the basic principles for better and safer public spaces and with maximum usage of art in public space, has as result a devastation of public sphere. Commercialization of public 
spaces has inevitably led them to informal privatization, which has as a consequence the segregation of public sphere in relation to economic status of the individual. Also, the idea of safe and clean, not only in formal physical characteristics, but to users also, has the discriminatory practices for homeless, i.e. to all those who could be suspicious in any way, and almost always those are not white people. So, "sweet and cozy" life from isolated Disney's world, which is available only to the high class, is provided on New Times Square by application of special BID rules administered by special private safety structures.

The characteristics of USA, and specially NYC, are public spaces in private ownership (Privately Owned Public Spaces - POPS), i.e. private property free for public use but under certain conditions and rules imposed by the owner (it's not common that these spaces have working hours or you can visit it with a pet or with a bag...). In fact, based on urban plan (Zoning Resolution from 1961.) investitures could have built extra space, if first on their land they create and enable the usage of one public space. During previous period, more than 500 public spaces has been built with more than 30 hectares of surface, and in different forms (arcades, plazas, parks, squares and similar) that has granted more than 300 buildings. Harvard Professor Jerold S. Kayden in one comprehensive study, co-made with city institutions and art association, has found that apart of $41 \%$ POPS used occasionally, $16 \%$ are used actively as a place of meetings and gathering of neighbors, $21 \%$ are used as places to rest and take a breath, $18 \%$ are used as a passage without stopping, while only $4 \%$ is renewed and redesigned. ${ }^{9}$ Surely POPS are directly connected with stimulated zoning, in other words with BID that is more frequently in favor of corporative profit, and not for public sphere improvement. Examples are redesign and changes in the way of using some of the most popular public spaces in NYC. Well designed public space of IBM is devastated as a consequence of ignoring POPS rules from the private interest. The similar happened with Sony public space (former AT\&T) which was transformed in semi-private one, through comprehensive process of design and legalization. Wrong planning and design approach to public space of Trump Tower, made the quality surrendered in front of the quantity.

Different examples of public spaces treatment are noticeable in BID Madison Avenue, Union Square, Columbus/Amsterdam or Bryant Park. On the territory of these districts there are a huge number of public city spaces like plazas and parks that are still generators of local community public life. In mentioned districts degree of direct corporative exploitation is less present or differently 
manifested than in New Times Square. In the sense it is possible to identify different public events and activities in public spaces that consequently lead to improvement of public sphere and life quality. Of course, like in any BID, degree of spontaneous public activity manifested through graffiti or any other public art in spatial and social context, has been reduced to a lowest level and made invisible in order to preserve the ideal about purity. Public art is replaced here with the art in public spaces that is mostly in context of capital - investors, fulfilling capricious requirements of corporative culture that is accepting public sphere in the way they want, and not as it really is.

In regard to public spheres and redesign of public spaces in USA, public sector doesn't have any different approach, especially for public spaces in front of state and public administration buildings. The best examples of this are Federal Plaza and Tilted Arc (1981-89), a project of well known artist Richard Serra who has gave the suggestion, in 1979, for redefinition of public space and public life. Serra, in his own suggestion has followed the specificity of physical space and natural surroundings, but also political and social significance of that place. For this concept, we can say that is democratic space where democracy takes place. Eight years after the moving of Tilted Arc, landscape architect Martha Schwartz has offered and realized new solution for Federal Plaza which was complete redesign of public space. New postmodern design not only brought a new name for plaza, Jacob Javits Plaza, but it has also satisfied all requirements of government sectors in sense of safety and control of users, introducing one completely new language and rules very close to philosophy coming from Disney's world. Using the art, this Project has managed to impose one type of restrictive usage, unlike Tilted Arc, and together with landscape architecture it offers friendly, not confronting design ${ }^{10}$ which despite all didn't succeed to give the previous quality and to satisfy high requirements of public sphere in relation with public city spaces.

Public criticism and dialogue established on this thematic field comes as the consequence of redefinition the position of an individual inside democratic, public sphere in front of established rules and relations imposed and created by corporative culture and sphere of private capital. The most common representatives/advocates of public sphere in this field is non-government sector, academic sphere and in certain cases an independent public institutions and services. In situation like this, private interest, that is, in absurd and logical way, closely connected with local governments and politics, is often using, to achieve its goals, the support of non government sector as proven trustee of public sphere, by quasi involvement in decision making process, in 
other words, it is consulting in order to win public support for realization of its interests, before they are politically confirmed. This kind of public sector organizing, through perfidy hiding beyond non- government sector is clearly telling about the readiness of capital to use all possibilities when their interests are in question. On the other hand, some of worldwide known organizations like Project for Public Space - PPS, known also as big critic of contemporary designed public spaces and follower of the idea of sociality, comfort and image of public spaces, that is possible to be realized through PPS concept known as 'petunia' beyond which are hidden different commercial contents (mostly services) which serve as generators of sociality, but at the same time as segregators on economic level. Thusly, with the time, the basic role of public space as a place where you can come publicly, or use it as individual or community, with granted freedom of usage regardless of social and economical status, has been lost. This role of public space is replaced with new role as the place with possible discrimination because of economic or social status; accordingly it has become basic efficient asset, weapon/tool for increase of private capital. In that sense, they are using any mean for creation of apparent philanthropy and welfare for everybody, offering possible users cheap entertainment and exclusive appearance of public spaces with discussable art values, and everything with the goal to daze eyes and senses by fast taking out of credit cards or ATM infusions.

\section{REAL APPARENT}

The fact that cities have kept the role of innovative places, where cultural life is generated from the aspect of quality and human relation toward community and surroundings, is proved by certain communities or groups of activists in the field of culture, art and environment. In that sense, it's still possible to find the examples of spontaneous urban life which promotes the idea of freedom and democracy, idea of care for an environment, society and individual, what gives us the trace of hope and faith that it's possible to develop better urban life. These examples are not remains of the past, but pioneers of the new age, corpus of the opinions opposite to corporate doctrine of exploitation and extra profit. Williamsburg in NYC, as the community gathering the new generation of artists and intellectuals can be one of the examples.

Williamsburg characterize strong community of artists (more than 3000) and mainly younger population that is not sharing values imposed by corporative culture. Actually, Williamsburg is the place of deserted and dislocated industry that was recycled for making residences or cultural and art spaces. During 
' 60 -ies of the last century, artists have moved to this district, and this expansion has continued and culminated during '90-ies, till today. Low rents and huge spaces suitable for ateliers, galleries and good connection with east side of lower Manhattan, have made this district very popular and attractive. What were in the past Soho and East Village couth by gentrification, today is Williamsburg. In one multiethnic community, synergy has been created and it represents alternative to commercial discourse, whose centre is on the other side of cost. Williamsburg with its intellectual and youth spirit offers the resistance and distance to corporative sugar candy for making consumers more stupid, in the frame of amusement and consumerism that aggressive capital is offering with its striking fist - urbanism. Ordinary street life, imperfect public spaces, activism on every step, public art in form of graffiti and other contextualized art work are just some of elements that are telling about us as creative but imperfect, weak creatures that don't have their space in Disney's world. How much public sphere and life in Williamsburg are magical shows the contrasting with the appearance of 'Disneylandization' of this district, with increasing enhance of private capital and initiative for building of exclusive housings and commercial places. It is generally known initiative and activity of owners of local small businesses for organizing and involvement into BID that will certainly make substantial changes in functioning and organization, and probably make this way of living in Williamsburg to completely disappear.

Is it possible to make and sustain successful public space where public life is generating by the trade? This is being shown in the best possible way by Reading Terminal Market in Philadelphia. RTM is non profit organization that gathers more than 80 selling places in the inner area of the supermarket. This is the oldest and the most known supermarket in USA coming from early colonial period, and it has been working from 1893. It is possible to buy there meat, fish, vegetables, fruits, flowers, books and clothes, and you can use services of many national restaurants. RTM presents for more than one hundred years of reminiscence of personal shopping and shopping in community, as the offer of everything for everybody. What creates this public market the special place is very good offer of goods from Amishes. RTM is place for gathering, fresh food shopping, conversations, lunch breaks, but also very important place for tourists. During the weekend RTM is visited by more than 100 thousand people, which makes it one of the busiest markets in the world. For sure RTM represents a positive example when private initiative is directed toward building of community and quality, that is permanently, generating and improving, creating tight connections with community, but having also good tradition of relations within it and with it. 
One completely different place, somewhere in between the city and suburbs of Philadelphia, represents industrial Brownfield where the small group of enthusiast has made Greensgrow Farm at the end of last century. This incredible urban agriculture is established on the surface of one block, on concrete and asphalt where they have organized hydroponic production of vegetable and flowers. This project of ecologically and economically sustainable food production is supported by Neighborhood Urban Agriculture Coalition (NUAC) and City Supported Agriculture (CSA). Greensgrow Farm does not use public water supply or electricity, but storage it or self-make it. Also for the starting of equipment and distribution of products, they are using biodiesel which is also made on the farm. Beside the full-time activists, there are a lot of volunteers from neighborhood and children for whom the special educational programs are made. It's not surprising that the Greensgrow Farm is one of the leaders in this area in US and they are often organizing seminars and workshops not only in US, but abroad as well. Greensgrow Farm beside production is known by cultivation and selling of seed material, agricultural and horticultural products as well as by distribution of healthy food to the restaurants in Philadelphia. There are a dozens of reasons to buy food made on local farms - it's healthy and good-quality food, buying it we are supporting local farmers, development of the local community and better quality of our environment. Greensgrow Farm is classical example of private space and capital which is in service for the community and neighborhood and is sending the clear message that accumulation of capital can be use for the well-being of everybody. That's the way how private capital is establishing Marxists model of production and distribution of capital.

\section{CONCLUSION}

'Disneylandization' of Times Square represents the best example of deserting the city as we know or we used to know with the real threat to become the prototype to cities of future. Privatization and globalization represent the phenomenon that are erasing social and cultural diversity, memory of the place and destiny of an individual. The last big event in Beijing which was the test of possibilities not only of architecture and building technology, but of political and economic possibilities as well. The fact that for the sake of building Olympic stadiums, millions of people were re-settled and millions of memories and destinies were destroyed, is showing that the power of the capital is unlimited and unstoppable. Something similar happened in Belgrade, when the city government, because of the upcoming International Student's Games, decided over the night to re-settle the whole Roma community from 
the neighborhood of sport's complex. The justification that they are trying to permanently solve the problem of hard life circumstances of Roma people actually was hiding typical racial discrimination, by hiding from the sight of the tourists the citizens of Belgrade who are leaving in deep poverty and who are "dirty Gypsies" as they call them. Industry of entertainment is offering to modern man/woman the alternative to idealess of intellectual and political elites which are unable to create healthy and sustainable life. By now, cities were characterized by tensions between private and public, in that way making the public sphere capable to make social and cultural innovations. Today, thanks to corporative globalism and consumer's culture, private silently prevailed, by presenting itself as public with its own rules of usage and consuming of instant amusement and consumption. On that way, public sphere is made like organized mass without clear identity and perception of self and the others. Corporate concept today is changing cities identities on the base of marketing touristic studies, and not on the base of real needs of people who are living and working there. Is it really true that our destiny is on the way to Disneyland? If it's true, am choosing the seat with the backwards view.

Disney's company has introduced revolution and established foundation for the economy of technology and amusement. Disney's thematic parks rise over ethnical, class and regional identities, offering in return national public culture based on aesthetization of differences and fear control . Disney's world is created in the way to become something inevitable, alter ego to modern western societies and collective fantasizes which are sources of many myths that the modern society is based on. This world is actually the materialization of the Hollywood "happy end" idea, the movie with continuous happy ending as the opium for the brain and deception for the eyes. 

University of New York, 1999.

Designs on the Public, Kristine F. Miller, University of Minnesota, Minneapolis, 2007.

Jacob Javits Plaza: Reconsidering Intentions, Ethnography of Place and Space: John Hill, Landscapes of Fear at The Graduate Center, CUNY, 2007.

Javna umetnost i kreiranje mesta, Zoran Đukanović i Jelena Živković, Arhitektonski fakultet Univerziteta u Beogradu, 2008.

http://www.justdisney.com/disneyland/history.html

http://www.nyc.gov/html/dcp/html/priv/priv.shtml

http://www.nyc.gov/html/sbs/html/neighborhood/bid.shtml

Urban Design Reader: Matthew Carmona \& Steve Tiesdell, Architectural Press, 2007. 